\title{
MATURAÇÃO NUCLEAR IN VITRO E MORTE CELULAR POR APOPTOSE EM OÓCITOS DE CAPRINOS NOS PERÍODOS SECO E CHUVOSO
}

\author{
Ricardo de Macêdo Chaves ${ }^{1}$, Filipe Queiros Gondim BeZerra ${ }^{2}$, PAUlo Fernandes de Lima ${ }^{3}$, \\ Marcelo Cavalcanti Rabelo ${ }^{4}$, Fabílola Paula-Lopes ${ }^{5}$, Marcos AnTÔNio Lemos de Oliveira ${ }^{3}$ \\ ${ }^{1}$ Professor Doutor da Universidade Estadual do Maranhão, São Luis, MA - rmchaves@ hotmail.com. \\ ${ }^{2}$ Medico Veterinário Doutor da Prefeitura Municipal de Ipojuca, Ipojuca, PE \\ ${ }^{3}$ Professor Doutor da Universidade Federal Rural de Pernambuco, Recife, PE \\ ${ }^{4}$ Analista Pernambuco Participações e Investimentos, Secretaria de Agricultura e Reforma Agrária, Recife, PE. \\ ${ }^{5}$ Professora Doutora da Universidade Federal de São Paulo, Diadema, SP.
}

\begin{abstract}
Este estudo teve como objetivo determinar a maturação nuclear in vitro e a morte celular por apoptose em oócitos caprinos. Os ovários de cabras foram coletados nos períodos seco (outubro a março) e chuvoso (abril a setembro), em abatedouros, e transportados ao Laboratório de Biotécnicas da Reprodução da UFRPE. Foram realizadas 12 repetições e os complexos cumulus oophorus foram colhidos de folículos entre 2 a $6 \mathrm{~mm}$ de diâmetro pela técnica de "slicing" e selecionados com base na morfologia. $\mathrm{O}$ experimento continha dois grupos: Grupo-1 (não maturados), avaliados logo após a colheita, e Grupo-2 (maturados in vitro), avaliados após a maturação de 24 horas em incubadora de $\mathrm{CO}_{2}$, na qual 25 oócitos foram colocados por gota em meio básico de maturação (MBM). Após a coleta dos oócitos do G-1 e G-

2, foi determinada a qualidade, por meio dos testes de atividade das enzimas caspases e o de fragmentação de DNA (TUNEL), com reagente PhiPhiLux $-\mathrm{G}_{1} \mathrm{D}_{2}$, sendo que no grupo G-2 a qualidade só foi determinada após maturação nuclear. Avaliou-se durante os estádios de maturação nuclear as fases de vesícula germinativa, rompimento da vesícula germinativa, metáfase I e II, não havendo diferença significativa $(P>0,05)$. Também não foi encontrada diferença significativa $(P>0,05)$ na atividade das enzimas caspases e na fragmentação do DNA dos oócitos não maturados e maturados in vitro. Com base nos dados obtidos, concluí-se que os períodos seco e chuvoso não exercem influência na maturação nuclear in vitro e na apoptose de oócitos da espécie caprina.
\end{abstract}

PALAVRAS-CHAVE: apoptose; caspases; complexos cumulus oophorus; folículos; teste TUNEL.

\section{IN VITRO NUCLEAR MATURATION AND CELL DEATH BY APOPTOSIS IN GOATS OOCYTES IN RAINY AND DRY PERIODS}

This study aimed to determine the in vitro nuclear maturation and cell death by apoptosis in goat oocytes. The ovaries of goats were collected during the dry (October-March) and rainy (April-September) seasons in slaughterhouses and transported to the Laboratory of Reproductive Biotechniques of UFRPE. Twelve repetitions were performed and cumulus oophorus were collected from follicles of 2-6 mm diameter using the technique of "slicing" and selected based on morphology. The experiment contained two groups: Group-1 (not matured), evaluated immediately after collection, and Group-2 (matured in vitro), assessed after 24 hours of maturation in a $\mathrm{CO}_{2}$ incubator, in which 25 oocytes per drop were placed in alkaline maturation (MBM). After collecting the oocytes from G-1 and G-2, the quality was determined by testing the enzyme activity of caspases and DNA fragmentation (TUNEL), using PhiPhiLux- $\mathrm{G}_{1} \mathrm{D}_{2}$ reagent, and in group G-2 the quality was only determined after nuclear maturation. During nuclear maturation stages, germinal vesicle, germinal vesicle breakdown and 
metaphase I and II were evaluated and no significant differences were found $(\mathrm{P}>0.05)$. There was also no significant difference (P>0.05) in enzymes activity of caspase and DNA fragmentation of oocytes matured and not matured in vitro. Based on the data obtained, it was concluded that rainy and dry seasons have no effect on in vitro nuclear maturation and apoptosis of goat oocytes.

KEYWORDS: Apoptosis; caspases; cumulus oophorus complexes; follicles; TUNEL test.

\section{INTRODUÇÃO}

A caprinocultura é hoje uma atividade do setor primário com expressivo potencial sócioeconômico em todas as regiões do Brasil, estimulando o desenvolvimento e criando novas possibilidades de agronegócio e de inclusão social. No entanto, a baixa produtividade e a falta de organização do sistema de produção limitam o aproveitamento dessa atividade no país (COSTA et al., 2008). A baixa produtividade dos rebanhos tem sido contornada por meio da importação de raças exóticas. Nesse contexto, o fator climático deve ser levado em consideração, devido ao estresse causado pela alta temperatura e umidade do ar (JORDAN, 2003).

Em oócitos bovinos maturados in vitro, a susceptibilidade à alta temperatura pode ser constatada tanto durante a fase de vesícula germinativa (VG) como durante o período de maturação oocitária (AL-KATANANI et al., 2002). Quando oócitos na fase de VG foram colhidos de vacas Holandesas expostas ao estresse térmico e submetidos à fecundação in vitro (FIV), houve redução no desenvolvimento embrionário até o estádio de blastocisto (ROCHA et al., 1998; ALKATANANI et al., 2002). O estresse térmico entre o estro e a inseminação artificial (IA) de novilhas (período de maturação oocitária) aumentou a proporção de embriões com desenvolvimento retardado (PUTNEY et al., 1989).

A susceptibilidade dos oócitos bovinos aos efeitos diretos da temperatura elevada durante a maturação in vitro (MIV) reduziu a maturação nuclear, a fecundação (ROTH \& HANSEN, 2005) e o desenvolvimento embrionário até o estádio de blastocisto (ROTH \& HANSEN, 2004a). A exposição de oócitos bovinos à temperatura severa de $42-43^{\circ} \mathrm{C}$ (EDWARDS \& HANSEN, 1996; ROTH \& HANSEN, 2004b) ou à temperatura elevada de $40-41^{\circ} \mathrm{C}$ durante as primeiras 12 horas de MIV bloqueou ou reduziu o desenvolvimento embrionário (EDWARDS \& HANSEN, 1996; ROTH \& HANSEN, 2004a).

A apoptose é um processo que utiliza ATP como fonte de energia no qual células danificadas são eliminadas de maneira a não causar danos ao tecido. O mecanismo de apoptose pode ser ativado de diversas maneiras, por meio de sinais extracelulares ou intracelulares gerados pela própria célula, sendo seu principal componente um grupo de enzimas proteolíticas conhecidas como caspases (MARTIN \& GREEN, 1995; NICHOLSON \& THORNBERRY, 1997; PEREZ et al., 1997). Morfologicamente, a apoptose caracteriza-se por agregação e condensação da cromatina (forma de meia-lua ou ferradura), condensação e fragmentação do núcleo, contração e condensação do citoplasma, protrusões da membrana plasmática, contração das organelas, formação de vacúolos citoplasmáticos, colapso da estrutura da célula, fragmentação celular sem extravasamento do conteúdo intracelular e formação de corpos apoptóticos (BROKER et al., 2005).

Recentemente, ROTH \& HANSEN, 2004a e ROTH \& HANSEN, 2005, demonstraram o efeito do estresse térmico sobre a apoptose oocitária. A exposição de oócitos ao estresse térmico durante as primeiras 12 horas de maturação aumentou a proporção de oócitos positivos para apoptose. O bloqueio da apoptose oocitária com inibidor de caspases (z-DEVD-fmk) (ROTH \& HANSEN, 2004a) ou com esfingolipídio (esfingosina-1-fosfato) resgatou os índices de clivagem e de desenvolvimento até o estádio de blastocisto (ROTH \& HANSEN, 2004b; MORITA et al., 2000).

Dessa forma, a caracterização e a manipulação dos mecanismos envolvidos na indução de apoptose oocitária após o estresse calórico representam alternativas para minimizar os efeitos negativos da temperatura elevada sobre a capacidade reprodutiva de fêmeas bovinas (ROTH \& HANSEN, 2004a, ROTH \& HANSEN, 2004b), o que pode se repetir em outra espécie como caprina. Diante do exposto, objetivou-se com este estudo determinar a maturação nuclear in vitro e a morte celular por apoptose em oócitos de caprinos comparando os períodos seco e chuvoso.

\section{MATERIAL E MÉTODOS}

Foi utilizado o modelo de estresse térmico 
calórico descrito por AL-KATANANI et al. (2002) para demonstrar os efeitos dos períodos do ano na capacidade de desenvolvimento dos oócitos. Os ovários foram colhidos de cabras no período seco (outubro a março) e chuvoso (abril a setembro). Os índices de temperatura e umidade do ar de cada mês foram obtidos com base nos dados climáticos das estações metereológicas estaduais (INMET, 2009).

Foram utilizados 1116 ovários de cabras SRD com idade variando de 12 a 46 meses, com escore de condição corporal (ECC) variando de 2,5 3,5 (escala de 1-5), adquiridas na região do semiárido pernambucano e abatidas no abatedouro Suimax, localizado na cidade de Igarassu, Região Metropolitana do Recife-PE (latitude $08^{\circ} 03^{\prime} 14^{\prime \prime} \mathrm{S}$, longitude $34^{\circ} 52^{\prime} 52^{\prime \prime} \mathrm{W}$ ). A temperatura ambiente mínima e máxima no período seco (outubro/2007 a março/2008) foi de 23 e $33^{\circ} \mathrm{C}$ e no chuvoso (abril a setembro/2008) de 18 e $31^{\circ} \mathrm{C}$, respectivamente. A umidade relativa média do ar foi de $71 \%$ no período seco e $85 \%$ no período chuvoso (INMET, 2009).

Em um período máximo de uma hora, os ovários foram transportados para o Laboratório de Biotécnicas da Reprodução do Departamento de Medicina Veterinária da Universidade Federal Rural de Pernambuco, em garrafa térmica contendo solução fisiológica em temperatura de $30^{\circ} \mathrm{C}$ acrescida de $30 \mu \mathrm{g} / \mathrm{mL}$ de sulfato de gentamicina (meio de transporte).

Os complexos cumulus oophorus (CCOs) foram colhidos pela técnica de fatiamento, "slicing", (produção de pequenas incisões simultâneas múltiplas na superfície do ovário com auxílio de um escarificador) dos folículos ovarianos que mediam de 2 a $6 \mathrm{~mm}$ de diâmetro. O líquido folicular foi depositado em placa de Petri contendo o meio de coleta (MC) constituído por $8,0 \mathrm{mg}$ de bicarbonato de sódio, 45,0 mg de glucose, 5,6 mg de piruvato de sódio, 11,9 mg de HEPES, 2,5 mg de sulfato de gentamicina e $20,0 \mathrm{mg}$ de álcool polivinílico em 50 $\mathrm{mL}$ de TALP.

Os CCOs foram selecionados morfologicamente de acordo com a classificação descrita por GONÇALVES et al. (2008) em Qualidade I (ooplasma homogêneo, cumulus compacto, contendo mais de três camadas de células), Qualidade II (ooplasma homogêneo, cumulus compacto parcialmente presente em volta do oócito ou rodeando completamente o oócito, com menos de três camadas celulares), Qualidade III (ooplasma homogêneo, cumulus presente, com apenas uma camada de célula ou ausência de camada de célula do cumulus - desnudos) e Qualidade IV (ooplasma com vacúolos e ou células do cumulus em regressão) e lavados três vezes no meio de coleta.
Em seguida, grupos de 20-25 CCOs foram maturados em gotas de $100 \mu \mathrm{L}$, no meio básico de maturação [MBM: TCM-199 suplementado com 50 $\mu \mathrm{g} / \mathrm{mL}$ de piruvato de sódio, $2,6 \mathrm{mg} / \mathrm{mL}$ de bicarbonato de sódio, $10 \%$ de soro fetal bovino (SFB), $50 \mu \mathrm{g} / \mathrm{mL}$ de sulfato de gentamicina, 20 $\mu \mathrm{g} / \mathrm{mL}$ de FSH/LH (Pluset ${ }^{\circledR}$ ) e $1 \mathrm{mg} / \mathrm{mL}$ de álcool polivinílico] sob óleo de parafina estéril, em estufa a $39^{\circ} \mathrm{C}$, com atmosfera úmida contendo $5 \%$ de $\mathrm{CO}_{2}$ durante 24 horas.

Foram realizadas 12 repetições em cada período do ano. No período seco foram colhidos 2914 oócitos (média de 231 por repetição) e no chuvoso, 2831 oócitos (média de 214 por repetição) de 554 e 562 ovários, respectivamente. Em cada repetição os CCOs foram divididos em dois grupos: no Grupo-1 os CCOs foram avaliados imediatamente após a colheita e no Grupo-2 os CCOs foram avaliados após a maturação in vitro (MIV).

No Grupo-1 os CCOs recém colhidos foram desnudados e inicialmente processados para determinação da atividade das enzimas caspases do grupo II com reagente PhiPhiLux- $\mathrm{G}_{1} \mathrm{D}_{2}$ (Oncoimmunin ${ }^{\circledR}$ ). Para realização deste procedimento, as amostras foram lavadas três vezes em gotas de $100 \mu \mathrm{L}$ de Phosphate-Buffered Saline (PBS) $+1 \mathrm{mg} / \mathrm{mL}$ de Polivinilpirrolidona (PVP) e incubadas em gotas de $25 \mu \mathrm{L}$ de PBS-PVP contendo $5 \mu \mathrm{M}$ de PhiPhiLux $-\mathrm{G}_{1} \mathrm{D}_{2}$ por 40 minutos a $39^{\circ} \mathrm{C}$ protegido da luz. Em seguida as amostras foram lavadas em PBS-PVP e a atividade enzimática caspase foi determinada com microscópio de fluorescência.

Após realizada a avaliação das enzimas caspases, outros oócitos foram fixados em uma solução de $4 \%$ de paraformaldeído por uma hora e armazenados em solução de $100 \mu \mathrm{L}$ de PhosphateBuffered Saline (PBS) $+1 \mathrm{mg} / \mathrm{mL}$ de polivinilpirrolidona (PVP) a $4^{\circ} \mathrm{C}$ até a realização do ensaio de TUNEL (terminal deoxynucleotidyl transferase-mediated dUTP nick end labeling). No dia do teste de TUNEL as amostras foram lavadas três vezes em gotas de $100 \mu \mathrm{L}$ PBS-PVP e incubadas em $15 \mu \mathrm{L}$ da mistura de TUNEL por uma hora a $37^{\circ} \mathrm{C}$. Em seguida, as amostras foram lavadas em PBS-PVP, incubadas com o corante de DNA DAPI por 15 minutos, lavadas em gotas de $100 \mu \mathrm{L}$ de PBSPVP, transferidas para lâminas e cobertas com lamínula e avaliadas em microscópio de fluorescência. Neste ensaio, o grupo 3'-OH do DNA fragmentado foi marcado com fluoresceína (FITC) por meio da reação enzimática mediada pela enzima deoxinucleotidil transferase (Tdt), a qual catalisa a polimerização de nucleotídeos modificados no terminal 3'-OH, como preconizaram PAULA- 


\section{LOPES \& HANSEN (2002) e ROTH \& HANSEN} (2004a).

No Grupo-2 (OMIV), os oócitos foram maturados in vitro. Após a maturação, foram desnudados no agitador mecânico Vortex ${ }^{\circledR}$, em meio $\mathrm{mDM}$ durante três minutos à velocidade " 7 " (escala 1-10), para determinação da atividade das enzimas caspases do grupo II (PhiPhiLux- $\left.\mathrm{G}_{1} \mathrm{D}_{2}\right)$ e fragmentação de DNA (TUNEL) como descritos anteriormente para o Grupo-1.

Após a maturação, outra parte dos oócitos foi desnudada no agitador mecânico Vortex ${ }^{\circledR}$, colocados entre lâmina e lamínula e fixados em etanol e ácido acético (3:1) por 12 horas e, posteriormente corados com orceína acética a 1\%, observando-os sob microscopia óptica de imersão (1000x). Imediatamente após a coloração, foram classificados como não definido (ND) oócitos em que não era possível identificar a fase da meiose devido à presença de células do cumulus ou da corona radiata (falha no processo de desnudamento); degenerado (DEG), oócitos que se apresentavam vacuolizados, não sendo possível a visualização dos cromossomos; vesícula germinativa (VG), núcleo definido, com ou sem nucléolo, sem condensação da cromatina; rompimento da vesícula germinativa (GVBD Germinative Vesicle Break-Down), final da prófase I com condensação da cromatina (Diacinese); metáfase I (MI), cromossomos já condensados formando a placa equatorial ou início da formação da mesma; anáfase I (AI), início da migração dos cromossomos para os polos da célula com fibras do fuso aparentes; telófase I (TI), cromossomos já nos polos, com fibras do fuso aparentes e metáfase II (MII), cromossomos formando a placa equatorial com o primeiro corpúsculo polar exteriorizado.
Para a estatística foi realizada análise de variância. Os resultados foram expressos em média e desvio padrão (análise de variância entre grupos). Considerando também as medidas tratadas em percentuais procedeu-se aos seguintes testes, primeiro uma comparação de variâncias, teste $F$ para variâncias com nível de significância de 5\% (P < $0,05)$. Depois um teste $t$ para comparação de médias, a 5\% de significância, para variâncias equivalentes ou variâncias distintas, conforme o que foi verificado no teste $F$ para variâncias (SAMPAIO, 2007).

\section{RESULTADOS}

No Grupo-1 não houve efeito dos períodos seco ou chuvoso na qualidade dos oócitos não maturados (Tabela 1). No Grupo-2, quando os oócitos foram maturados in vitro não houve efeito do período do ano na porcentagem de oócitos de Qualidade I ou II. No entanto, a proporção de oócitos com Qualidade III foi maior $(\mathrm{P}<0,05)$ no período seco, enquanto que a média e desvio padrão de oócitos com Qualidade IV foi maior $(\mathrm{P}<0,05)$ na estação chuvosa (Tabela 2). Não foi verificada diferença significativa $(\mathrm{P}>0,05)$ quando comparados média e desvio padrão da maturação in vitro de oócitos de fêmeas abatidas no período seco $(64,08 \pm 6,88)$ e chuvoso $(66,75 \pm 9,22)$ (Tabela 2).

Nos oócitos do Grupo-2, as médias e desvio padrão dos oócitos DEG, ND, VG, GVBD, MI, AI e MII não apresentaram diferença significativa $(\mathrm{P}>0,05)$ em relação ao período do ano. No entanto, as médias e desvio padrão dos oócito na TI foi maior $(\mathrm{P}<0,05)$ no período chuvoso em relação ao seco (Tabela 3).

Tabela 1- Média e desvio padrão da qualidade de oócitos não maturados (Grupo-1) avaliados após colheita em cabras abatidas na região Metropolitana do Recife nos períodos seco e chuvoso

\begin{tabular}{ccc}
\hline & \multicolumn{2}{c}{ Período do ano } \\
\cline { 2 - 3 } Qualidade dos oócitos não maturados & Seco & Chuvoso \\
& $\mathrm{n} /(\bar{x} \pm \mathrm{s})$ & $207 / 17,25 \pm 3,46^{\mathrm{a}}$ \\
\hline Qualidade I (QI) & $199 / 16,58 \pm 3,28^{\mathrm{a}}$ & $325 / 27,08 \pm 4,81^{\mathrm{a}}$ \\
Qualidade II (QII) & $316 / 26,33 \pm 5,22^{\mathrm{a}}$ & $339 / 28,25 \pm 5,95^{\mathrm{a}}$ \\
Qualidade III (QIII) & $380 / 31,66 \pm 5,21^{\mathrm{a}}$ & $494 / 43,16 \pm 7,35^{\mathrm{a}}$ \\
Qualidade IV (QIV) & $577 / 46,08 \pm 9,65^{\mathrm{a}}$ & $1365^{\mathrm{a}}$ \\
\hline Total & $1472^{\mathrm{a}}$ &
\end{tabular}

Letras minúsculas diferentes nas linhas indicam diferenças significativas $(\mathrm{P}<0,05)$ pelo teste $F$.

$\mathrm{n}=$ número de oócitos não maturados, $\bar{x}=$ média, $\mathrm{s}=$ desvio padrão da qualidade os oócitos. 
Tabela 2 - Média e desvio padrão da qualidade dos oócitos do Grupo-2 avaliados após maturação in vitro obtidos de cabras abatidas na região Metropolitana do Recife nos períodos seco e chuvoso

\begin{tabular}{lcc}
\hline \multirow{2}{*}{ Qualidade dos oócitos maturados in vitro } & \multicolumn{2}{c}{ Período do ano } \\
\cline { 2 - 3 } & $\mathrm{n} /(\bar{x} \pm \mathrm{s})$ & $\begin{array}{c}\text { Chuvoso } \\
\mathrm{n} /(\bar{x} \pm \mathrm{s})\end{array}$ \\
\hline Qualidade I (QI) & $196 / 16,33 \pm 3,08^{\mathrm{a}}$ & $173 / 14,41 \pm 3,28^{\mathrm{a}}$ \\
Qualidade II (QII) & $288 / 24,00 \pm 4,32^{\mathrm{a}}$ & $256 / 21,33 \pm 3,62^{\mathrm{a}}$ \\
Qualidade III (QIII) & $412 / 34,33 \pm 4,03^{\mathrm{a}}$ & $327 / 27,25 \pm 5,80^{\mathrm{b}}$ \\
Qualidade IV (QIV) & $546 / 45,50 \pm 9,92^{\mathrm{a}}$ & $710 / 59,16 \pm 9,59^{\mathrm{b}}$ \\
\hline Maturação in vitro & $841 / 64,08 \pm 6,88^{\mathrm{a}}$ & $874 / 66,75 \pm 9,22^{\mathrm{a}}$ \\
\hline Total & $1442^{\mathrm{a}}$ & $1466^{\mathrm{a}}$ \\
\hline Letras minúsculas diferentes nas linhas indicam diferenças significativas $(\mathrm{P}<0,05)$ pelo teste $F$. & \\
$\mathrm{n}=$ numero de oócitos maturados in vitro, $\bar{x}=$ média, $\mathrm{s}=$ desvio padrão.
\end{tabular}

Tabela 3 - Média e desvio padrão do estádio de maturação nuclear dos oócitos de fêmeas caprinas abatidas na região Metropolitana do Recife em relação aos períodos seco e chuvoso

\begin{tabular}{|c|c|c|}
\hline \multirow[b]{2}{*}{ Estádio de Maturação Nuclear } & \multicolumn{2}{|c|}{ Período do ano } \\
\hline & $\begin{array}{c}\text { Seco } \\
\mathrm{n} /(\bar{x} \pm \mathrm{s})\end{array}$ & $\begin{array}{c}\text { Chuvoso } \\
\mathrm{n} /(\bar{x} \pm \mathrm{s})\end{array}$ \\
\hline Degenerados (Deg) & $56 / 7,57 \pm 0,12^{a}$ & $50 / 6,68 \pm 0,32^{\mathrm{a}}$ \\
\hline Não Definido (ND) & $47 / 6,32 \pm 0,21^{\mathrm{a}}$ & $36 / 5,45 \pm 0,14^{\mathrm{a}}$ \\
\hline Vesícula Germinativa (VG) & $27 / 3,53 \pm 0,11^{\mathrm{a}}$ & $33 / 4,12 \pm 0,22^{\mathrm{a}}$ \\
\hline Rompimento da Vesícula Germinativa (GVBD) & $89 / 12,24 \pm 1,43^{\mathrm{a}}$ & $84 / 11,65 \pm 1,37^{\mathrm{a}}$ \\
\hline Metáfase I (MI) & $63 / 8,86 \pm 0,98^{\mathrm{a}}$ & $52 / 7,88 \pm 1,05^{\mathrm{a}}$ \\
\hline Anáfase I (AI) & $34 / 5,32 \pm 0,37^{\mathrm{a}}$ & $36 / 5,45 \pm 0,41^{\mathrm{a}}$ \\
\hline Telófase I (TI) & $32 / 4,92 \pm 0,45^{\mathrm{a}}$ & $55 / 7,55 \pm 0,49^{\mathrm{b}}$ \\
\hline Metáfase II (MII) & $421 / 62,43 \pm 5,98^{\mathrm{a}}$ & $455 / 64,41 \pm 6,76^{\mathrm{a}}$ \\
\hline Total & $769^{\mathrm{a}}$ & $801^{\mathrm{a}}$ \\
\hline
\end{tabular}

Letras minúsculas diferentes nas linhas indicam diferenças significativas $(\mathrm{P}<0,05)$ pelo teste $F$.

$\mathrm{n}=$ número de oócitos, $\bar{x}=$ média, $\mathrm{s}=$ desvio padrão da maturação nuclear.

A atividade das enzimas caspases não foi afetada pelo período do ano $(\mathrm{P}>0,05)$ tanto nos oócitos do Grupo-1 quanto do Grupo-2 (Figura 1). Nos oócitos não maturados (Grupo-1), a atividade de caspases foi $9,44 \%$ no período seco e $8,57 \%$ no chuvoso. Quando avaliada após a maturação in vitro, a atividade enzimática das caspases foi $11,57 \%$ no período seco e $8,73 \%$ no chuvoso (Figura 1).

Da mesma forma, a porcentagem dos oócitos com fragmentação do DNA TUNEL-positivos não foi afetada pelo período do ano $(\mathrm{P}>0,05)$, tanto em oócito do Grupo-1 quanto do Grupo-2 (Figura 2). No Grupo-1 a proporção dos oócitos não maturados TUNEL-positivo foi $10,86 \%$ no período seco e 9,08\% no chuvoso. Nos oócitos do Grupo-2 a porcentagem dos oócitos TUNEL-positivo foi $11,31 \%$ no período seco e $9,86 \%$ no chuvoso (Figura 2). 


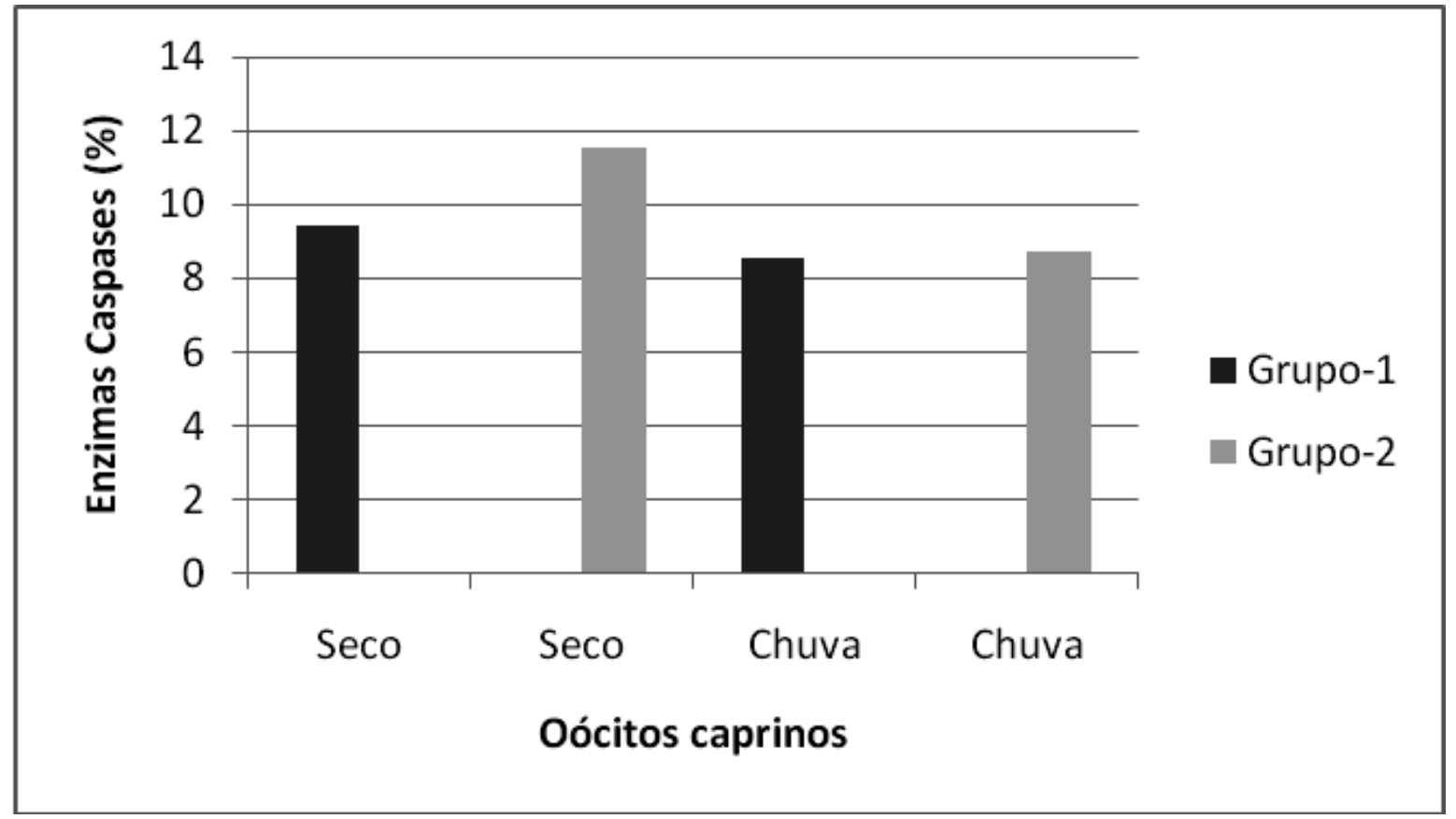

Figura 1 - Porcentagem de oócitos não maturados (Grupo-1) e maturados in vitro (Grupo-2) positivo para atividade das enzimas Caspase do grupo II na espécie caprina $(\mathrm{P}<0,05)$ pelo teste $\mathrm{T}$ nos períodos seco e chuvoso.

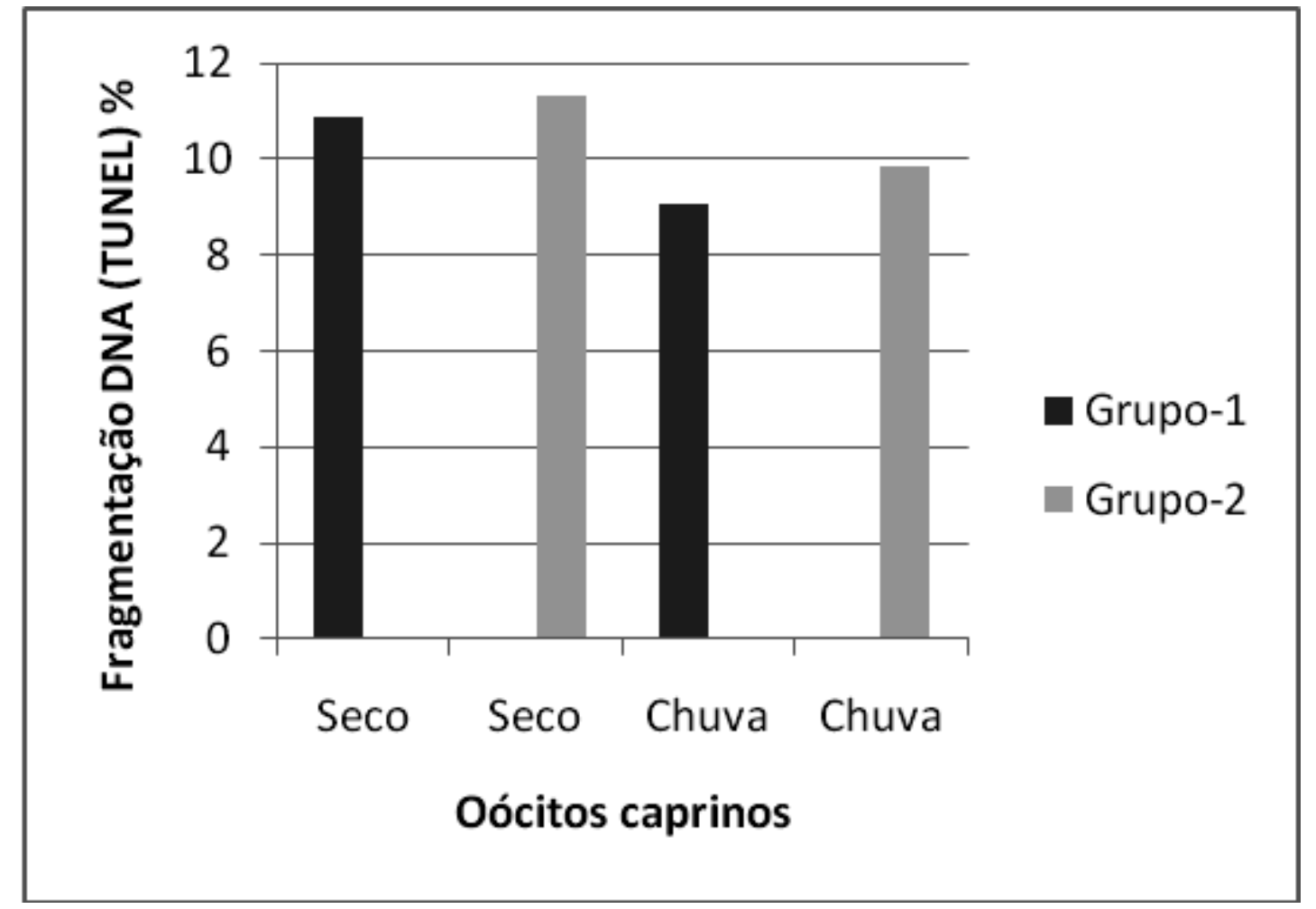

Figura 2 - Porcentagem de oócitos não maturados (Grupo-1) e maturados in vitro (Grupo-2) TUNEL-positivo (fragmentação de DNA) na espécie caprina $(\mathrm{P}<0,05)$ pelo teste $\mathrm{T}$ nos períodos seco e chuvoso. 


\section{DISCUSSÃO}

Os resultados obtidos na análise da maturação nuclear in vitro dos oócitos coletados nos períodos secam e chuvoso estão próximos aos obtidos por PAULA et al. (2008) e CARNEIRO (2008), quanto às médias de maturação in vitro. As taxas de metáfase II obtidas neste estudo explicam-se pelo fato de que, em cultivo in vitro, uma menor quantidade de oócitos completa a maturação nuclear devido à pouca quantidade ou ausência de células do cumulus. Segundo CECCONI et al. (2007), em oócitos com qualidade III e IV, foi observada maior quantidade de oócitos nas fases intermediárias da meiose como a fase de telófase I, mas sem interferência nos resultados da maturação nuclear obtidos para a espécie caprinas.

As médias dos CCOs com qualidade QI e QII apresentando cumulus compacto com mais de três camadas de células foi pequena quando comparadas com os de qualidade QIII e QIV, como encontrado por CHAVES et al. (2010). Esses autores concluíram que o diâmetro folicular não exerce influência sobre a qualidade dos CCOs recuperados de fêmeas caprinas, o que aumenta a importância das células do cumulus. Já CECCONI et al. (2007) observaram que a qualidade acaba diminuindo a capacidade de maturação nuclear in vitro devido também a fatores internos da célula, como a integridade do ooplasma que pode dificultar a chegada à fase de metáfase II na espécie caprina, explicando, possivelvemnte, o número reduzido de oócitos que atingem a metáfase II quando comparado a bovinos (CARNEIRO, 2008).

Uma adequada seleção dos CCOs, conforme afirmado por CECCONI et al. (2007), permite aumentar as taxas de maturação nuclear in vitro, diminuindo variações nos resultados. Com oócitos cobertos com três ou mais camadas completas e aderidas de células do cumulus ou com cumulus intacto, ooplasma homogêneo, de coloração marrom e sem grânulos rugosos, é possível conseguir melhores resultados do que com oócitos com cumulus incompleto ou expandido. Autores como YANG et al. (1990) e HAZAKEGER \& STUBBINGS (1992) observaram o mesmo. Todavia, em caprinos, o emprego dos CCOs na maturação, não obedece a critérios rígidos, variando desde aqueles com cumulus compacto até os que apresentam apenas uma camada de células do cumulus (MARTINO et al., 1994; IZQUIERDO et al., 1999). Segundo SUTOVSKY et al. (1993), a expansão in vitro do cumulus é visível a partir de 12 horas de maturação e a presença considerável de glicosaminoglicanos destas células impede a ação do estresse oxidativo dos radicais livres sobre os oócitos, evitando a redução na taxa de maturação e clivagem (LUVONI et al., 1996), e bloqueia do choque térmico a síntese de proteínas que protegem os oócitos durante a maturação in vivo e in vitro (EDWARDS \& HANSEN, 1997).

VINOLES et al. (2002), FATEHI et al. (2005) e CECCONI et al. (2007) demonstraram em seus estudos que a condição fisiológica da doadora, o escore corporal, raça, idade e variação individual, têm merecido grande atenção, pois esses fatores interferem diretamente na qualidade dos CCOs recuperados. Diferente dos resultados aqui obtidos, RUBIANES \& MENCHACA (2003), também trabalhando com ovários de cabras de matadouro, não encontraram diferenças na qualidade dos CCOs entre animais jovens (a partir de 18 meses) e senis (até 17 anos), embora tenham notado redução na produção de gametas nos animais mais velhos.

Neste estudo, a idade, a raça e o escore corporal das fêmeas foram bastante variados, aumentando a importância dos fatores individuais das cabras doadoras de oócitos, os quais, quando produzidos por fêmeas em condições nutricionais diversas, podem interferir diretamente na qualidade dos CCOs maturados do Grupo-2. Esses fatos justificam as diferenças observadas nos oócitos que foram maturados de qualidades III e IV, obtidos nos períodos secos e chuvosos, respectivamente, neste estudo, já que a temperatura ambiental não teve grandes variações em ambos os períodos.

Apenas uma fração dos oócitos expostos a temperaturas do ambiente sofreram apoptose. Segundo ROTH \& HANSEN (2004b), existem componentes inter e intra-celulares que definem se um oócito pode reagir a essas agressões naturais do ambiente. Em suínos, TATEMOTO et al. (2000) observaram que as células do cumulus parecem ter um papel fundamental na proteção dos oócitos contra apoptose induzida por estresse oxidativo. Devido a esses e a outros fatores anteriormente citados não foram observadas neste estudo diferenças nos níveis de apoptose encontrados nos oócitos caprinos em ambos os períodos. Já EDWARDS \& HANSEN (1996) e KOLLE et al. (2003), concluíram que células do cumulus fornecem termo-proteção para oócitos bovinos e, talvez, a integridade e a função dos CCOs possam afetar a capacidade de sobreviver a uma maturação oocitária após estresse térmico, o que pode justificar que oócitos não maturados apresentem menos alterações que os maturados in vitro, observado pelas taxas de maturação in vitro obtidas em caprinos neste experimento, levando-se 
em conta que a maior quantidade dos CCOs recuperados neste estudo apresentaram qualidade III e IV.

ROTH \& HANSEN (2004b), quando pesquisaram a competência do desenvolvimento e resistência de oócitos bovinos sob condições de estresse térmico, evidenciaram que as altas temperaturas do ambiente, mesmo que dentro de intervalos fisiológicos, podem ser um estímulo à morte celular programada em oócitos mamíferos. No presente estudo, as porcentagens de apoptose permaneceram dentro de padrões fisiológicos, não sendo observados aumentos também em associação com a atividade da caspase, já que as temperaturas registradas variaram aproximadamente dois a cinco graus em função do período, sendo mais influenciadas, como explicado por FATEHI et al. (2005) e CECCONI et al. (2007), por fatores nutricionais e físicos. Conforme observado por VAN BLERKOM \& DAVIS (1998), a fragmentação do DNA celular nos oócitos não é sempre um resultado da ativação da cascata de caspase e, portanto, é possível que pequenas variações térmicas produzido pelas temperaturas ambientais associadas aos fatores acima não tenham sido suficientes para induzir níveis de atividade caspase e fragmentação nuclear para produzir um complemento total de mudanças associadas à apoptose que possam ser observadas nas células nessas condições, independente da temperatura e do período do ano.

\section{CONCLUSÃO}

Com base nos dados obtidos, podemos concluir que os períodos do ano seco e chuvoso não exercem influência na maturação nuclear in vitro e na apoptose de oócitos da espécie caprina.

\section{AGRADECIMENTOS}

Agradecemos à Empresa Suimax, a diretores e funcionários por disponibilizar os animais necessários à execução deste experimento.

\section{REFERÊNCIAS}

AL-KATANANI, Y. M.; PAULA-LOPES, F. F.; HANSEN, P. J. Effect of season and exposure to heat stress on oocyte competence in Holstein cows. Journal Dairy Science. v.85, p.390-396, 2002.

BROKER, L.E.; KRUYT, F. A. E.; GIACCONE, G. Cell death independent of caspases: a review. Clinic Cancer Research. v.11, p.3155-3162, 2005.

CARNEIRO, G. F. Biotécnicas da reprodução assistida em pequenos ruminantes. Tecnologias e Ciência
Agropecuária, v.2, p.23-28, 2008.

CECCONI, S.; MAURO, A.; CAPACCHIETTI, G.; BERARDINELLI, P.; BERNABÒ, N.; DI VINCENZO, A. R.; MATTIOLI, M.; BARBONI, B. Meiotic Maturation of Incompetent Prepubertal Sheep Oocytes Is Induced by Paracrine Factor(s) Released by Gonadotropin-Stimulated Oocyte-Cumulus Cell Complexes and Involves Mitogen-Activated Protein Kinase Activation. Endocrinology, v.149, n.1, p.100-107, 2007.

CHAVES, R. M.; AGUIAR FILHO, C.; SANTOS JÚNIOR, E.; ALMEIDA FILHO, J. M.; LIMA, P. F.; OLIVEIRA, M. A. L. Efeito do diâmetro folicular sobre a qualidade dos oócitos obtidos de ovários de ovelhas (Ovis aries) e cabras (Capra hircus). Ciência Animal Brasileira, v. 11, n. 3, p. 683-688, 2010.

COSTA, R. G.; ALMEIDA, C.C.; PIMENTA, FILHO, E. C.; HOLANDA JUNIOR, E. V.; SANTOS, N. M. Caracterização do sistema de produção caprino e ovino no Brasil. Archivos de Zootecnia, v.57, n.218, p.196-205. 2008.

EDWARDS, J. L.; HANSEN, P. J. Differential responses of bovine oocytes and preimplantation to heat shock. Molecular Reproduction and Development, v.46, p.138-145, 1997.

EDWARDS, J. L.; HANSEN, P. J. Elevated temperature increases heat shock protein 70 synthesis in bovine twocell embryos and compromises function of maturing oocytes. Biology of Reproduction. v.55, p.340-346, 1996.

FATEHI, A. N.; ROELEN, B. A. J.; COLENBRANDER, B.; SCHOEVERS, E. J.; GADELLA, B. M.; BEVERS, M. M.; VAN DEN HURK, R. Presence of cumulus cells during in vitro fertilization protects the bovine oocyte against oxidative stress and improves first cleavage but does not affect further development. Zygote, v.13, n.2, p. 177-185, 2005.

GONÇALVES, P. B. D.; OLIVEIRA, M. A. L.; MEZZALIRA, A.; MONTAGNER, M. M.; VISINTIN, J. A.; COSTA, L. F. S. Produção in vitro de embriões. In: GONÇALVES, P. B. D.; FIGUEIREDO, J. R.; FREITAS, J, V. F. ( $2^{\mathrm{a}}$ Ed.), Biotécnicas aplicadas à reprodução animal. Editora Roca, São Paulo, p.261-292, 2008.

HAZAKEGER, N. L.; STUBBINGS, R. B. Developmental potential of selected bovine oocyte cumulus complexes. Theriogenology, v. 37, n.2, p. 219, 1992.

INMET. Instituto Nacional de Meteorologia. Disponível em: <http:www.inmet.gov.br/html/prev_climatica_tempo/ prognostico>. Acesso em: 23 abr. 2009.

IZQUIERDO, D.; VILLAMEDIANA, P.; PARAMIO, M.T. Effect of cultura media on embryo development from prepubertad gota IVM-IVF oocytes. Theriogenology, v.52, n.5, p. 847-861, 1999.

JORDAN E. R. Effects of heat stress on reproduction. 
Journal of Dairy Science, v.86, p.104-114, 2003.

KOLLE, S.; STOJKOVIC, M.; BOIE, G.; WOLF, E.; SINOWATZ, F. Growth hormone-related effects on apoptosis, mitosis, and expression of connexin 43 in bovine in vitro maturation cumulus oophorus complexes. Biology of Reproduction, v.68, p.1584-589, 2003.

LUVONI, G. C.; KESKINTEPE, L.; BRACKETT, B. G. Improvement in bovine embryo production in vitro by glutathione-containing media. Molecular Reproduction and Development, v.43, p.437-443, 1996.

MARTIN, S. J.; GREEN, D. R. Protease activation during apoptosis: death by a tuousand cust. Cellular, v.82, p.349352, 1995.

MARTINO, A.; MOGAS, T.; PALOMO, M. J. Meiotic competence prepubertal goat oocytes. Theriogenology, v. 41, n.5, p. 969-980, 1994.

NICHOLSON, D. W.; THORNBERRY, N. A. Caspases: killer proteases. Trends in Biochemical Science, v.8, p.299-306, 1997.

PAULA, N. R. O.; CARDOSO, J. F. S.; OLIVEIRA, M. A. L.; FREITAS, V. J. F. Embriões caprinos produzidos in vivo ou in vitro: técnicas, problemas e perspectivas. Revista Brasileira de Reprodução Animal, Belo Horizonte, v.32, n.1, p.21-35, 2008.

PAULA-LOPES, F. F.; HANSEN P. J. Apoptosis is an adaptative response in bovine preimplantation embryos that facilitates survival after heat shock. Biochemical Biophys Research Communicator, v.295, p.37-42, 2002.

PEREZ, G. I.; KNUDSON, C. M.; LEYKIN, L.; KORSMEYER, S. J.; TILLY, J. L. Apoptosis-associated signaling pathways are required for chemotherapymediated female germ cell destruction. Natural Medical, v.3, p.1228-1332, 1997.

PUTNEY, D. J.; DROST, M.; THATCHER, W. W. Influence of summer heat stress on pregnancy rates of lactating dairy catle following embryo transfer or artificial insemination. Theriogenology, v.31, n.4, p.765-778, 1989.

ROCHA, A.; RANDEL, R. D.; BROUSSARD, J. R.; LIM, J. M.; BLAIR, R. M.; ROUSSEL, J. D.; GODKE, R. A.; HANSEL, W. High environmental temperature and humidity decrease oocyte quality in Bos taurus but not in Bos indicus cows. Theriogenology, v.49, n.4, p.657-665,
1998.

ROTH, Z.; HANSEN, P. J. Disruption of nuclear maturation and rearrangement of cytoskeletal elements in bovine oocytes exposed to heat shock during maturation. Reproduction, v.129, p.235-244, 2005.

ROTH, Z.; HANSEN, P. J. Involvement of apoptosis in disruption of developmental competence of bovine oocytes by heat shock during maturation. Biology of Reproduction, v.71, p.1898-1906, 2004a.

ROTH, Z.; HANSEN, P. J. Sphingosine 1-phosphate protects bovine oocytes from heat shock during maturation. Biology of Reproduction, v.71, p.2072-2078, 2004b.

RUBIANES, E.; MENCHACA, A. The pattern and manipulation of ovarian follicular growth in goats. Animals Reproduction Science, v. 78, p. 271-287, 2003.

SAMPAIO, I. B. M. Estatística Aplicada a Experimentação Animal, $3^{\text {a }}$ Ed.. Belo Horizonte: FEPMVZ, 2007. $264 \mathrm{p}$.

SUTOVSKY, P.; FLECHON, J.E.; FLECHON, B.; MOTLIK, J.; PEYNOT, N.; CHESNE, P.; HEYMAN, Y. Dynamic changes of gap junctions and cytoskeleton during in vitro of culture of cattle oocyte cumulus complexes. Biology of Reproduction, v.49, p.1277-1287, 1993.

TATEMOTO, H.; SAKURI, N.; MUTO, N. Protection of porcine oocytes against apoptosis cell death caused by oxidative stress during in vitro maturation: role of cumulus cells. Biology of Reproduction, v.63, p.805-810, 2000.

VAN BLERKOM, J.; DAVIS, P. W. DNA strand break and phosphatidyserine redistribution in newly ovulated and culture mouse and human oocytes: occurrence and relationship to apoptosis. Humana Reproduction, v.13, p.1317-1324, 1998.

VINOLES, C.; FORSBERG, M.; BANCHERO, G.; RUBIANES, E. Ovarian follicular dynamics and endocrine profiles in Polwarth ewes with high and low body condition. Animal Science, v.74, p.539-545, 2002.

YANG, N. S.; LU, K. H.; GORDON, I. In vitro fertilization (IVF) and culture (IVC) of bovine oocytes from stored ovaries. Theriogenology, v. 33, n.2, p. 352$359,1990$. 